\title{
Partitioning of methyl internal rotational barrier energy of thioacetaldehyde
}

\author{
NIKHIL GUCHHAIT \\ Department of Chemistry, Indian Institute of Technology, North Guwahati, \\ Guwahati 781 039, India \\ e-mail: nikhil@iitg.ernet.net
}

MS received 30 January 2001; revised 2 July 2001

\begin{abstract}
The nature of methyl internal rotational barrier in thioacetaldehyde has been investigated by relaxation effect, natural bond orbital (NBO) analysis and Pauling exchange interactions. The true experimental barrier can be obtained by considering fully relaxed rotation. Nuclear-electron attraction term is a barrier forming term in the fully relaxed rotation, but it appears as an antibarrier for rigid rotation. It is seen that during methyl rotation, the torsional mode is coupled with the aldehydic hydrogen out-of-plane wagging motion. Natural bond orbital analysis shows that the principal barrier forming term originates from the $\mathrm{C}-\mathrm{C}$ bond. The lengthening of the $\mathrm{C}-\mathrm{C}$ bond is explained by considering charge transfer interaction between several bonding and antibonding orbitals in the $\mathrm{C}-\mathrm{C}$ bond region, which leads to higher bonding overlap for the eclipsed conformer compared to the staggered conformer. $\mathrm{S}-\mathrm{C}(\sigma) / \mathrm{C}_{\mathrm{me}}-\mathrm{H}_{\mathrm{ip}}$ and $\mathrm{C}-\mathrm{H}_{\mathrm{ald}} / \mathrm{C}_{\mathrm{me}}-\mathrm{H}_{\mathrm{op}}$ interactions appear to be the main barrier-forming Pauling exchange terms but have less contribution to make to the barrier compared to the $\mathrm{C}-\mathrm{C}$ bond interaction.
\end{abstract}

Keywords. Methyl rotation; natural bond orbitals; Pauling exchange interaction; thioacetaldehyde.

\section{Introduction}

Study of internal rotational barriers of small groups has drawn much attention from both theoretical and experimental points of view for the last few decades. Experimental information on the barrier and the dynamics on methyl internal rotation is becoming increasingly available ${ }^{1,2}$. Laser spectroscopic techniques have been coupled with improved system preparation techniques to understand more about the internal rotation in the ground and higher excited states of molecules. Internal rotation has been studied from the theoretical point of view and the potential energy surfaces governing large amplitude motions have been calculated directly by ab initio molecular orbital procedures ${ }^{3-6}$.

Recently, the role of lone-pair electrons on methyl internal rotational barrier of dimethyl ether and its homologues has been analysed theoretically. Ab initio calculations have been carried out and various contributions to the barrier (e.g. Pauling exchange steric repulsion, $\sigma$-lone-pair reorganization and $\pi$ hyperconjugation) have been dissected $^{7,8}$. The combined results of natural bond orbital, symmetry partitioning and relaxation analyses demonstrate that the $\sigma$-lone pair plays an important role in controlling the rotational barrier. The methyl rotational barriers for acetaldehyde and acetone were chosen for in-depth analysis because these molecules are simple and exhibit highly 
resolved microwave, Raman and Rydberg spectra ${ }^{9,10}$. For example, the methyl rotational barrier for acetaldehyde estimated from the well-resolved microwave and IR spectra was found to be $400 \mathrm{~cm}^{-1}$ (Hougen et al) ${ }^{11}$. Simulated $a b$ initio calculations revealed the importance of coupling between methyl torsion and acetaldehyde-hydrogen wagging as a determinant for the barrier shape ${ }^{12}$. Well-establishd $\pi$ fragment model by Hehre, Pople and Devaquet ${ }^{13}$ proposed that methyl rotational barrier in acetaldehyde is based on $\pi$ interaction. Another suggestion regarding methyl rotational barrier in acetaldehyde included Pauling repulsion forces between the electron clouds in $\mathrm{C}-\mathrm{H}$ bonds involving the $\mathrm{C}_{\mathrm{me}} \mathrm{H}-\mathrm{CH}_{\mathrm{ald}}$ in the metastable state, breaking of the weak covalent bond between carbonyl oxygen lone-pair and the eclipsed methyl hydrogen, and dipole polarization effect on the methyl $\mathrm{C}-\mathrm{H}$ bonds driven by the large $\mathrm{C}=\mathrm{O}$ dipole ${ }^{14}$. Goodman et al ${ }^{15}$ carried out ab initio calculations at several levels and decomposed the barrier energy for methyl internal rotation in acetaldehyde into $\sigma$ and $\pi$ symmetry components. These led them to conclude that the $\sigma$ component of the $\Delta V_{n e}$ is the principal barrier forming term. This is, however, contrary to the results from the $\pi$ fragment model ${ }^{13}$. Very recent NBO analysis ${ }^{16}$ showed that the large barrier-forming energy terms arise from the weakening of $\mathrm{C}-\mathrm{C}$ and methyl $\mathrm{C}-\mathrm{H}$ out-of-plane bonds. It was also shown that the weakening of the $\mathrm{C}-\mathrm{C}$ bond in acetaldehyde originated from the antibond character introduced into the $\mathrm{C}-\mathrm{C}$ bond region by charge transfer between the $\mathrm{C}_{\mathrm{me}}-\mathrm{H}_{\mathrm{ip}}$ bonding and $\mathrm{C}-\mathrm{H}_{\mathrm{ald}}$ antibonding orbitals.

Thioacetaldehyde is the sulphur analogue of acetaldehyde where oxygen atom of the acetaldehyde is replaced by sulphur atom. Spectroscopic studies on acetaldehyde and acetone were competently carried out in order to know the frequency of torsional and other modes for both ground and excited states. Interest on thiocarbonyl molecules has grown rapidly due to the fact that little is known about them as compared to the corresponding carbonyls. Parallel development in the study of thiocarbonyl compounds was hampered by factors, such as, the instability leading to polymerization and obnoxious smell. However, Kroto et al determined the value of the torsional barrier as $549.8 \mathrm{~cm}^{-1}$ by analysing the rotational line splitting from microwave spectrum ${ }^{17}$. Moule et al did visible and UV spectral studies for unstable species like thioacetaldehyde and thioacetone using pyrolysis jet spectroscopic technique ${ }^{18-22}$. Their analysis of the thioacetaldehyde spectrum revealed that the torsional motion in the upper state is coupled with the large amplitude wagging motion of aldehyde hydrogen. The observed phase shift in the torsional angle on electronic excitation was suggested to be due to the effects of hyperconjugation between methyl hydrogen and the $\mathrm{C}-\mathrm{S} \pi$ orbitals. They estimated the rotational energy barrier to be $534.3 \mathrm{~cm}^{-1}$ from the band interval in the visible spectrum. $A b$ initio calculation provided the rotational barrier as $458.0 \mathrm{~cm}^{-1}$ where the wagging mode of aldehydic hydrogen was coupled to the methyl torsion ${ }^{22}$.

The discrepancy in rotaional barrier energy between the experimental and the calculated values, especially the lower value obtained by the theoretical computation, might owe its origin to the use ${ }^{21}$ of a relatively less quantitative model. What was done previously was that the two-dimensional Schroedinger equations were framed for the torsional and wagging motions and subsequently solved to obtain the barrier energy and shape of the potential energy surfaces. Moreover, the origin of the rotational barrier was, to the best of our knowledge, not addressed earlier. The knowledge of energy involved in the rotational barrier is believed to be very important in the context of reaction chemistry. In view of the above considerations, it was felt important to gain in-depth understanding about the internal rotational barrier during the rotational process by a rather powerful and 
relatively more quantitative approach. In the present investigation, the origin of the methyl internal rotational barrier in thioacetaldehyde has been evaluated by first dividing the barrier energy into relaxation effect, NBO analysis and Pauling exchange interactions. The results of our endeavour are presented in this paper.

\section{Computational methods}

$\mathrm{HF} / 6-311 g(d)$ basis set has been employed in geometry optimization and NBO analysis. The virial theorem is satisfied with a discrepency of about $6 \%$ of the barrier, i.e. $\Delta T=$ $-\Delta E$ is $30 \mathrm{~cm}^{-1}$. The calculations have been done by Gaussian 94 program ${ }^{23}$ at Tohoku University, Quantum Chemistry Lab Computer Facility.

Geometry optimization has been carried out with HF and MP2 levels with the above basis set with a very tight option of the Gaussian 94 software. The relaxation calculation has been done at the same level with the same basis set.

The natural bond orbital (NBO) ${ }^{24}$ calculations have been carried out using the NBO $\operatorname{program}^{25}$ of the Gaussian 94. It may be mentioned that Foster and Wienhold have shown the utility of natural hybrid orbitals in describing the umbrella inversion of ammonia $^{26}$. Steric calculations have been done by the Badenhoop and Weinhold procedure using NBOs to obtain the Pauling exchange terms ${ }^{27}$.

\section{Results and discussion}

\subsection{Geometry}

The MP2/6-311 $g(d)$ optimized geometries for both eclipsed $(E)$ and staggered $(S)$ conformers are shown in figure 1 . The eclipsed ground state geometry at the bottom of the barrier, the staggered conformer at the top-of-the barrier and different conformer geometries obtained by $\mathrm{CH}_{3}$ rotation are obtained from the ab-initio calculation with HF/6-311 $g(d)$ basis set. The results are summarized in table 1. The difference between staggered and eclipsed conformers is attributed mainly to the lengthening of the $\mathrm{C}-\mathrm{C}$ bond by $0.008 \AA$, and the expansion 6 the $\mathrm{CCH}_{\text {ald }}$ bond angle by $1.2^{\circ}$. It is relevant to note that the parallel structural changes induced by methyl rotation in acetaldehyde are the lengthening of the $\mathrm{C}-\mathrm{C}$ bond by $0.007 \AA$ and the expansion of the $\mathrm{CCH}_{\mathrm{ald}}$ bond angle by $1.5^{\circ} 16$. These results are in order because the replacement of $\mathrm{O}$ by $\mathrm{S}$ in going from acetaldehyde to thioacetaldehyde is expected to show a more pronounced effect, as is observed. Moreover, during the course of methyl rotation in thioacetaldehyde, the out-ofplane hydrogen bond length decreases, whereas the in-plane methyl hydrogen bond increases. Also $\mathrm{C}-\mathrm{S}$ bond length is increased in the staggered conformer by $0.0006 \AA$. The nonequivalence in the $\mathrm{CCH}_{\text {methyl }}$ angles in both eclipsed and staggered conformers is caused by $2.3^{\circ}$ and $1.6^{\circ}$ tilt angles in the eclipsed and staggered conformers respectively.

\subsection{Barrier energy}

Overall partitioning of total electronic energy change during methyl rotation from the bottom-of-the-well ( $c f$ eclipsed) to top-of-the-barrier ( $c f$ staggered) conformation is given by the equation,

$$
\Delta E=\Delta T+\Delta V_{\mathrm{ee}}+\Delta V_{\mathrm{nn}}+\Delta V_{\mathrm{ne}},
$$



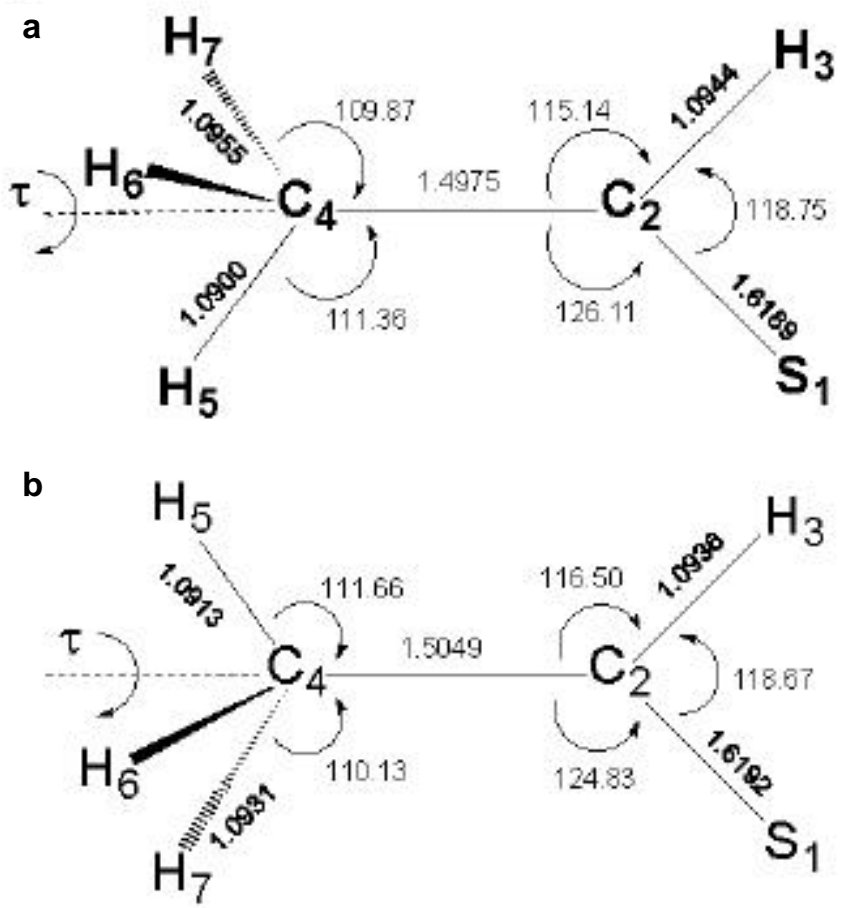

Figure 1. MP2/6-311 $g(d)$ optimized geometries for thioacetaldehyde. (a) Equilibrium eclipsed $(E)$ and $(\mathbf{b})$ top-of-barrier staggered $(S)$ conformers. The angle of rotation of methyl group along $\mathrm{C}-\mathrm{C}$ bond is expressed by $\tau$.

where $\Delta E$ is the $a b$ initio calculated electronic energy difference between the thioacetaldehyde staggered $(S)$ and eclipsed $(E)$ conformers, and $\Delta T, \Delta V_{\text {ee }}, \Delta V_{\text {nn }}$ and $\Delta V_{\text {ne }}$ are the differences in kinetic, electron-electron repulsion, nuclear-nuclear repulsion and the nuclear-electron attraction energy terms respectively. The attractive and repulsive contributions to the total energy change are $\Delta V=\Delta V_{\text {ne }}$ and $\Delta T+\Delta V_{\mathrm{r}}$, respectively, where $\Delta V_{\mathrm{r}}=\Delta V_{\mathrm{ee}}+\Delta V_{\mathrm{nn}}$.

Here the calculations are done for rigid, partially relaxed and fully relaxed methyl group rotations. The quantity of interest is the difference between the individual energy terms for the staggered and the corresponding eclipsed conformers. The virial theorem, $-\Delta E=\Delta T$, is satisfied reasonably well with the HF/6-311 $g(d)$ basis set.

The torsional angle $(\tau)$ dependence of the nuclear virial for the rigid and the fully relaxed forms of the molecule are shown in figure 2 . For the rigid rotation, like in the case of acetaldehyde, it increases monotonically as the rotation proceeds. But for the fully relaxed rotation, the change in the nuclear virial with the rotation of the methyl group is very small. Figure 3 shows the $\tau$ dependence of the aldehyde hydrogen wagging angle, calculated in a manner similar to that done for acetaldehyde. It predicts a maximum wagging angle of $2.8^{\circ}$ for a $\tau$ value of $30^{\circ}$. The inference drawn from this is that during methyl rotation, the torsional mode is strongly coupled with the out-of-plane wagging motion of the aldehydic hydrogen. Incidentally, a similar observation was made by Moule et al in their studies involving a two-dimensional Schrodinger equation ${ }^{22}$. 
Table 1. Thioacetaldehyde HF/6-311 $g(d)$ optimized geometrical parameters for different internal rotations of methyl group conformers ${ }^{\mathrm{a}}$.

\begin{tabular}{|c|c|c|c|c|c|}
\hline \multirow{2}{*}{$\begin{array}{l}\text { Geometrical } \\
\text { parameter }\end{array}$} & \multicolumn{5}{|c|}{ Torsional angle $\tau$} \\
\hline & $0^{\circ}$ & $15^{\circ}$ & $30^{\circ}$ & $45^{\circ}$ & $60^{\circ}$ \\
\hline \multicolumn{6}{|l|}{ Bond length } \\
\hline $\mathrm{C}_{2}-\mathrm{S}_{1}$ & 1.6047 & 1.6048 & 1.6049 & 1.6051 & 1.6053 \\
\hline $\mathrm{C}_{2}-\mathrm{H}_{\mathrm{ald}}$ & $1 \cdot 0812$ & $1 \cdot 0811$ & $1 \cdot 0808$ & 1.0804 & 1.0803 \\
\hline $\mathrm{C}_{2}-\mathrm{C}_{4}$ & 1.4955 & 1.4965 & 1.4993 & 1.5025 & $1 \cdot 5034$ \\
\hline $\mathrm{C}_{4}-\mathrm{H}_{\mathrm{ip}}$ & $1 \cdot 0800$ & $1 \cdot 0802$ & $1 \cdot 0808$ & 1.0821 & 1.0827 \\
\hline $\mathrm{C}_{4}-\mathrm{H}_{\mathrm{op}}$ & 1.0869 & $1 \cdot 0862$ & 1.0851 & 1.0840 & $1 \cdot 0838$ \\
\hline \multicolumn{6}{|l|}{ Bond angle } \\
\hline $\mathrm{H}_{\mathrm{al}} \mathrm{C}_{2} \mathrm{~S}_{1}$ & $118 \cdot 62$ & $118 \cdot 58$ & $118 \cdot 49$ & $118 \cdot 42$ & $118 \cdot 39$ \\
\hline $\mathrm{H}_{4} \mathrm{C}_{2} \mathrm{~S}_{1}$ & $126 \cdot 79$ & $126 \cdot 67$ & $126 \cdot 35$ & 125.99 & $125 \cdot 77$ \\
\hline $\mathrm{C}_{4} \mathrm{C}_{2} \mathrm{H}_{\text {ald }}$ & 114.59 & 114.75 & $115 \cdot 16$ & 115.58 & $115 \cdot 84$ \\
\hline $\mathrm{C}_{2} \mathrm{C}_{4} \mathrm{H}_{\mathrm{ip}}$ & $111 \cdot 84$ & 111.74 & $111 \cdot 41$ & $111 \cdot 81$ & 111.65 \\
\hline $\mathrm{C}_{2} \mathrm{C}_{4} \mathrm{H}_{\mathrm{op}}$ & $109 \cdot 53$ & $109 \cdot 63$ & $109 \cdot 93$ & $110 \cdot 38$ & $110 \cdot 01$ \\
\hline \multicolumn{6}{|c|}{ Dihedral angle } \\
\hline $\mathrm{C}_{4} \mathrm{C}_{2} \mathrm{~S}_{1} \mathrm{H}_{\text {ald }}$ & $180 \cdot 0$ & $178 \cdot 06$ & $177 \cdot 18$ & $178 \cdot 0$ & $180 \cdot 0$ \\
\hline $\mathrm{H}_{\mathrm{op}} \mathrm{C}_{4} \mathrm{C}_{2} \mathrm{H}_{\mathrm{ip}}$ & $121 \cdot 56$ & $121 \cdot 41$ & $120 \cdot 97$ & $120 \cdot 27$ & $121 \cdot 02$ \\
\hline Tilt angle ${ }^{\mathrm{b}}$ & $2 \cdot 31$ & $2 \cdot 11$ & 1.48 & 1.43 & 1.64 \\
\hline
\end{tabular}

${ }^{\mathrm{a}}$ Bond lengths and angles are in $\AA$ and degrees respectivelyatom numbering is shown in figure 1 ; torsional angle $\tau$ refers to the rotation of methyl group along the $\mathrm{C}-\mathrm{C}$ bond axis; 'tilt angle is the difference in angle between $\mathrm{C}_{\mathrm{me}} \mathrm{CH}_{\mathrm{ip}}$ and $\mathrm{C}_{\mathrm{me}} \mathrm{CH}_{\mathrm{op}}$ angles.

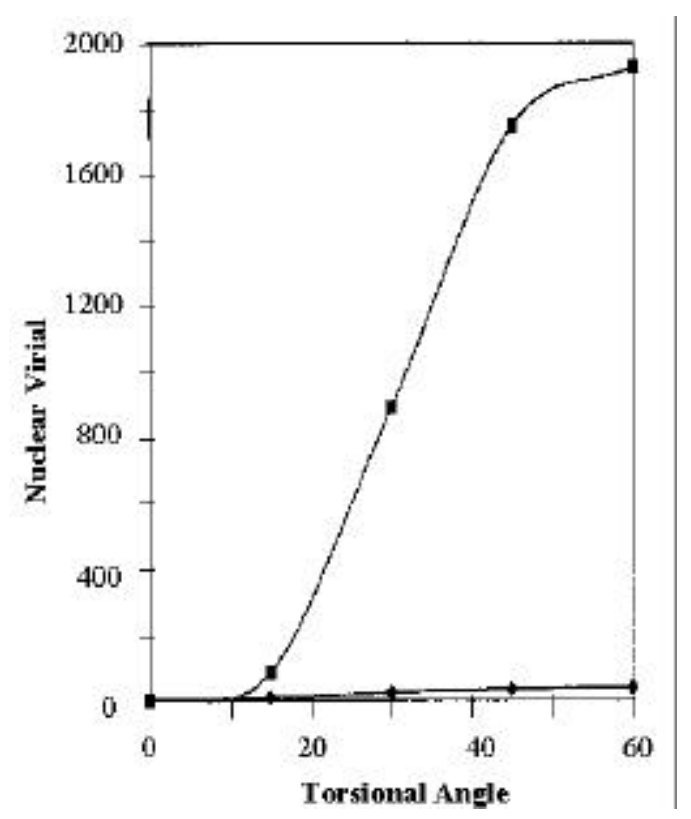

Figure 2. The dependence of nuclear virial of thioacetaldehyde for rigid ( $\square$ ) and fully relaxed $(\diamond)$ rotation on the methyl torsional angle $(\tau)$. 


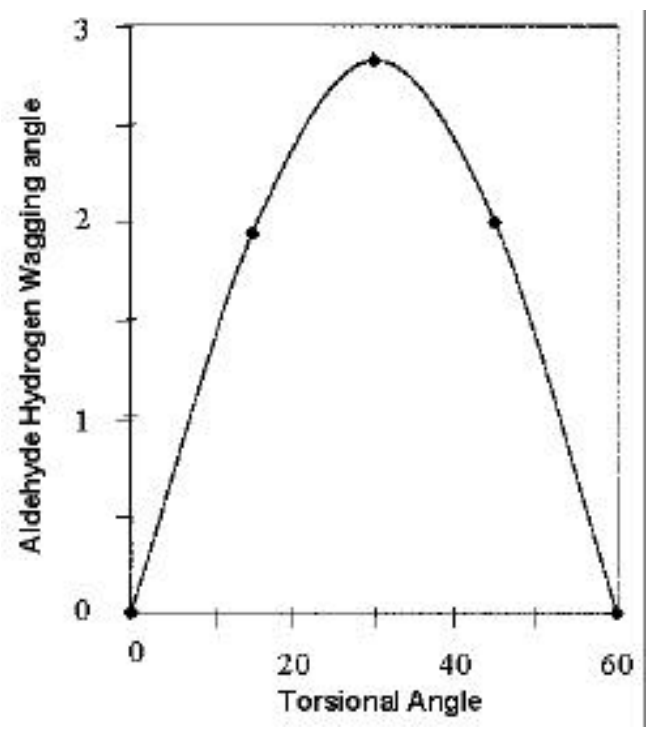

Figure 3. Dependence of aldehyde hydrogen out-of-plane wagging angle on the methyl torsional angle $(\tau)$.

Table 2. Thioacetaldehyde internal rotation barrier partitioned into symmetry terms $\mathrm{cm}^{-1}$ a.

\begin{tabular}{|c|c|c|c|c|c|}
\hline & $\begin{array}{l}\text { Fully } \\
\text { relaxed }\end{array}$ & $\underset{\text { rotation }^{b}}{\text { Rigid }}$ & $\begin{array}{c}\mathrm{C}-\mathrm{C} \\
\text { relaxed }^{\mathrm{c}}\end{array}$ & $\begin{array}{c}\mathrm{C}-\mathrm{S} \\
\text { relaxed }^{\mathrm{c}}\end{array}$ & $\begin{array}{l}\text { Methyl } \\
\text { relaxed }\end{array}$ \\
\hline Barrier & 548 & 584 & 574 & 584 & 572 \\
\hline Kinetic energy $(\Delta T)$ & 518 & 1585 & -1739 & 1216 & 2477 \\
\hline Virial theorem discrepancy & 30 & 2168 & -1165 & 1800 & 3049 \\
\hline Nuclear nuclear repulsion $\left(\Delta V_{\mathrm{nn}}\right)$ & -5879 & 8731 & -24616 & 5022 & 6170 \\
\hline Electron repulsion $\left(\Delta V_{\mathrm{ee}}\right)$ & -1851 & 11510 & -21251 & 7785 & 8386 \\
\hline Nuclear electron attraction $\left(\Delta V_{\mathrm{ne}}\right)$ & 8795 & -21242 & 48181 & -13440 & -16460 \\
\hline
\end{tabular}

${ }^{a}$ Difference in energy terms $(\mathrm{HF} / 6-311 g(d))$ between staggered $\left(180^{\circ}\right)$ and equilibrium eclipsed $\left(0^{\circ}\right)$ conformers (figure 1). Values are nearest whole number; ${ }^{\mathrm{b}}$ methyl group rotated by $180^{\circ}$ with all bond lengths and angles are frozen at eclipsed conformer geometry; ${ }^{c}$ rigid rotation followed by given bond length or bond angle relaxed to its fully relaxed value

The energy terms are all presented in table 2. Notable in the context is that Moule et $a l^{22}$ found 534.3 and $458.0 \mathrm{~cm}^{-1}$ as the methyl rotational barrier energy from the results of visible jet spectrum analysis and $a b$ initio calculation respectively. Significantly, our calculated values for the fully relaxed rotational barrier is $548 \mathrm{~cm}^{-1}$, showing far better agreement with the experimental barrier of $549.8 \mathrm{~cm}^{-1}$ as measured by microwave spectroscopy ${ }^{17}$. Partitioning of the barrier energy into kinetic and potential energy terms shows that $\Delta V_{\text {ne }}$ appears to be the only barrier-forming term in the fully relaxed rotation. For rigid and other relaxed rotations (except $\mathrm{C}-\mathrm{C}$ relaxed), $\Delta V_{\mathrm{ne}}$ appears as an antibarrier term, while $\Delta T, \Delta V_{\text {ee }}$ and $\Delta V_{\mathrm{nn}}$ appear as barrier-forming terms. It is seen that the inclusion of $\mathrm{C}-\mathrm{C}$ relaxation to any other relaxation shows $\Delta V_{\mathrm{ne}}$ to be the barrier-forming 
term whereas the rest of the energy terms are antibarrier in nature ${ }^{28}$. Thus, the present results state that $\mathrm{C}-\mathrm{C}$ bond relaxation appears to be the major contributing factor for the barrier in thioacetaldehyde.

\subsection{Natural bond orbital analysis}

The natural bond orbital (NBO) analysis transforms molecular orbital wave functions into one-centre (lone pair) and two-centre (bond) representations ${ }^{29}$. This kind of categorization represents a chemically appealing point of view, since it highlights the individual bonds and lone pairs that play a role in the chemical process ${ }^{30}$. The diagonal elements of the Fock matrix in an NBO representation represent the energies of localized bonds, antibonds and lone pair, while the off-diagonal elements represent bond-antibond, lone-pair-antibond and normally small antibond-antibond interactions.

This scheme is used to differentiate the barrier energy into bond and lone pair energies, bond-antibond and lone pair-antibond interactions, and steric repulsions. The interactions involving the Rydberg orbitals are not considered to be important since these interactions have weak orientational dependence.

\subsection{Bond energies}

The change in bond energy $(\Delta \omega)$ during methyl internal rotation for thioacetaldehyde is shown in table $3^{7,8,16}$, and has been obtained from the relation,

$$
\Delta \omega=\varepsilon_{S} \rho_{S}-\varepsilon_{E} \rho_{E},
$$

where $\varepsilon_{S}$ and $\varepsilon_{E}$ are the NBO energies for the staggered and eclipsed conformers respectively, and $\rho_{S}$ and $\rho_{E}$ are the corresponding NBO electron occupancies ${ }^{7,16}$. Since our interest lies in the principal barrier-forming terms, only the important interactions are listed in table 3 . The largest barrier forming term, by far, is the change in bond energy

Table 3. Principal barrier-forming bond and lone-pair energy terms for thioacetaldehyde at rigid, partially and fully relaxed methyl rotational conformers $\left(\mathrm{cm}^{-1}\right)^{\mathrm{a}}$.

\begin{tabular}{|c|c|c|c|c|c|c|}
\hline & $\mathrm{S}-\mathrm{C}(\sigma)$ & $\mathrm{C}-\mathrm{C}_{\mathrm{me}}$ & $\mathrm{C}_{\mathrm{me}}-\mathrm{H}_{\mathrm{ip}}$ & $\mathrm{C}_{\mathrm{me}}-\mathrm{H}_{\mathrm{op}}$ & $\mathrm{LP}(1)$ & $\mathrm{LP}(2)$ \\
\hline Fully relaxed ${ }^{\mathrm{b}}$ & 790 & 2522 & 322 & -908 & 361 & 354 \\
\hline Rigid rotation $^{c}$ & 145 & -169 & -1086 & 289 & 489 & 594 \\
\hline $\mathrm{C}-\mathrm{C}_{\mathrm{me}}$ relaxed $^{\mathrm{d}}$ & -83 & 2622 & -1275 & 36 & 436 & 524 \\
\hline $\mathrm{C}-\mathrm{S}$ relaxed $^{\mathrm{d}}$ & 407 & -197 & -1102 & 278 & 477 & 579 \\
\hline $\mathrm{C}_{\mathrm{me}}-\mathrm{H}_{\mathrm{ip}}$ and $\mathrm{C}-\mathrm{S}$ relaxed ${ }^{\mathrm{d}}$ & 182 & 2594 & -1291 & 26 & 419 & 509 \\
\hline Methyl relaxed ${ }^{\mathrm{d}}$ & 145 & -229 & 377 & -656 & 466 & 537 \\
\hline $\mathrm{C}_{\mathrm{me}}-\mathrm{H}_{\mathrm{ip}}$ and methyl relaxed $\mathrm{d}^{\mathrm{d}}$ & -83 & 2553 & 188 & -902 & 409 & 471 \\
\hline $\mathrm{C}-\mathrm{S}$ and CCS angle relaxed $\mathrm{d}^{\mathrm{d}}$ & 903 & -159 & 937 & 300 & 362 & 568 \\
\hline
\end{tabular}

${ }^{\mathrm{a}} \Delta \omega$ (calculated from equation in the text), the population-weighted natural bond orbital energy difference for the staggered and eclipsed conformers, values are nearest whole numbers; ${ }^{b}$ fully relaxed rotation; ${ }^{c}$ methyl group rotated by $180^{\circ}$ with all bond lengths and angles are frozen at eclipsed conformer; 'rigid rotation followed by given bond length and angle extended to its fully relaxed staggered conformer Abbrev. $\mathrm{H}_{\mathrm{op}}$ : out-of-plane methyl hydrogen atom, $\mathrm{H}_{\mathrm{ip}}$ : in-plane methyl hydrogen atom, $\mathrm{C}_{\mathrm{me}}$ : methyl carbon atom, LP (1) and LP (2): lone pair. 
involving the $\mathrm{C}-\mathrm{C}$ bond $\left(2522 \mathrm{~cm}^{-1}\right)$ for a fully relaxed rotation. This $\mathrm{C}-\mathrm{C}$ bond energy, however, becomes anti-barrier for a rigid rotation. Interestingly the investigation reveals that the $\mathrm{C}-\mathrm{C}$ relaxation (row 3, table 3) alone provides $2622 \mathrm{~cm}^{-1}$ barrier, a value which is quite close to the fully relaxed value. This therefore suggests that $\mathrm{C}-\mathrm{C}$ relaxation is the controlling factor for the barrier.

The second highest contribution to the barrier is the C-S $\sigma$ bond energy $\left(800 \mathrm{~cm}^{-1}\right)$ which is about one third that of the $\mathrm{C}-\mathrm{C}$ bond barrier contribution. From table 3 (row 8) it is clear that the barrier-forming bond energy $\left(800 \mathrm{~cm}^{-1}\right)$ originates from both the $\mathrm{C}-\mathrm{S}$ bond relaxation and the CCS angle relaxation. Unlike in acetaldehyde, $\mathrm{C}-\mathrm{H}_{\mathrm{op}}$ bond in thioacetaldehyde appears to be anti-barrier. This can be assumed to arise from the shortening of the $\mathrm{C}-\mathrm{H}_{\mathrm{op}}$ bond at the top of the barrier. The $\mathrm{C}-\mathrm{H}_{\mathrm{ip}}$ bond appears as a small barrier-forming term of about $332 \mathrm{~cm}^{-1}$ for the fully relaxed rotation and can easily be gained from the methyl-relaxed rotation. Therefore, it is evident that in addition to the main barrier-forming $\mathrm{C}-\mathrm{C}$ bond energy, the $\mathrm{C}-\mathrm{S}$ bond and the methyl $\mathrm{C}-\mathrm{H}_{\mathrm{ip}}$ hydrogen contribute to the methyl rotational barrier to some extent.

\subsection{Lone-pair energy}

There are two localized lone-pairs on the sulphur atom in thioacetaldehyde, similar to that of the oxygen atom in acetaldehyde. One of the lone-pairs is nearly of $p$ character while the other one lies along the $\mathrm{C}-\mathrm{S}$ bond. The sulphur lone-pair energy change in going from one conformer to the other is shown in table 3 . Both are about $350 \mathrm{~cm}^{-1}$ (barrier-forming) and are not affected appreciably by relaxation.

\subsection{Bond-antibond interaction}

The bond-antibond and lone-pair-antibond interactions can be calculated by two different procedures following the NBO method ${ }^{5}$. The first one involves an indirect procedure initiated by Weinhold, which involves comparison of barrier energies calculated with and without the Fock matrix element, $F_{i j}{ }^{*}$, between the bonding (or lone pair) NBO and a virtually unoccupied antibonding orbital, deleted ${ }^{31}$. The second one involves the calculation of $F_{i j} *^{2} /\left(\varepsilon_{i}-\varepsilon_{j}\right)$ using second-order perturbation theory.

The results of our calculation using the second-order perturbation method are shown in table 4. There are a number of barrier-forming bond-antibond interaction terms. The most important ones are $\mathrm{C}-\mathrm{H}_{\mathrm{op}} / \mathrm{S}-\mathrm{C}(\sigma)^{*}, \mathrm{C}-\mathrm{H}_{\mathrm{ip}} / \mathrm{C}-\mathrm{H}_{\mathrm{al}}{ }^{*}, \mathrm{C}-\mathrm{H}_{\mathrm{ald}} / \mathrm{C}-\mathrm{H}_{\mathrm{ip}}{ }^{*}, \mathrm{C}-\mathrm{H}_{\mathrm{op}} / \mathrm{S}-\mathrm{C}(\pi)^{*}$ and $\mathrm{S}-\mathrm{C}(\pi) / \mathrm{C}-\mathrm{H}_{\mathrm{op}}$ *. The orbital contour diagrams show that all these interactions involve charge transfer of electrons from a bonding orbital to an antibonding orbital. The highest barrier-forming bond-antibond interaction, $1077 \mathrm{~cm}^{-1}$, arises from $\mathrm{C}-\mathrm{H}_{\mathrm{op}}$ bonding and $\mathrm{S}-\mathrm{C}(\sigma)^{*}$ antibonding orbitals. Figure $4 \mathrm{a}$ depicts such an interaction for the eclipsed conformer showing significant overlap of the orbitals (the Fock matrix element is 0.057 a.u.). In contrast, a similar orbital contour plotted in figure $4 \mathrm{~b}$ for the staggered conformer shows a decrease in the overlap (Fock matrix is 0.009 a.u.). A markedly decreased overlap explains why these types of interaction involving the charge transfer of electrons from one bonding orbital to the other antibonding orbital are causing the antibarrier.

The second highest term is the interaction between the $\mathrm{C}-\mathrm{H}_{\mathrm{ip}}$ bond and the $\mathrm{C}-\mathrm{H}_{\text {ald }}$ antibond $\left(1032 \mathrm{~cm}^{-1}\right)$ which is incidently similar to that of acetaldehyde $\left(1169 \mathrm{~cm}^{-1}\right)^{16}$. Figures $5 \mathrm{a}$ and $\mathrm{b}$ show the contour diagrams of these interactions for both eclipsed and 

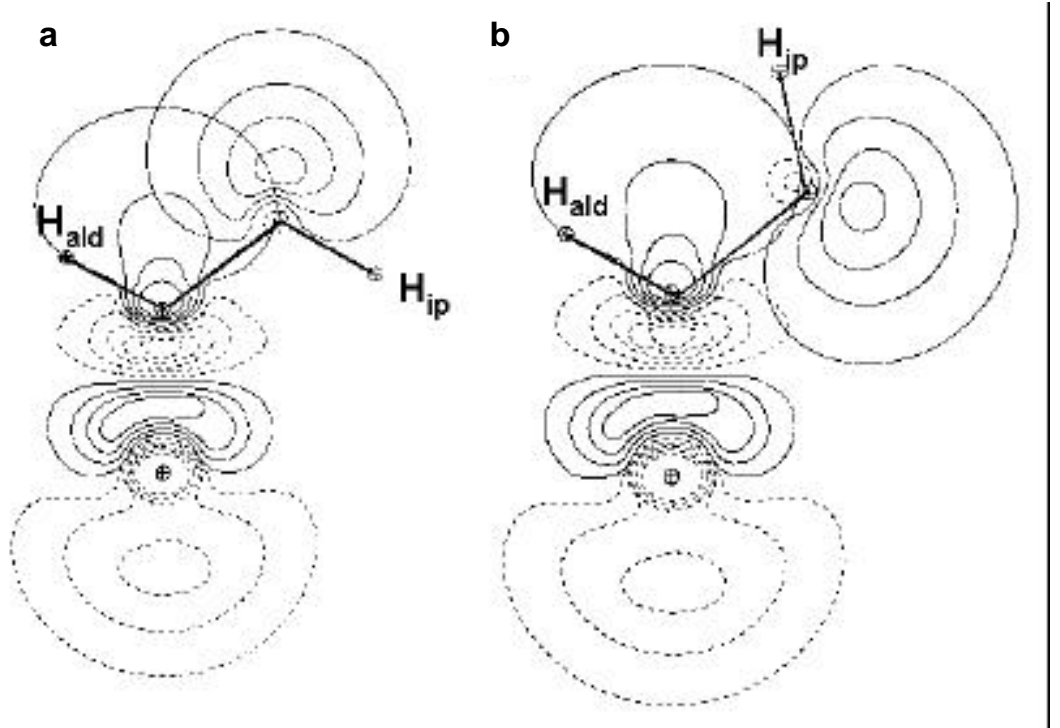

Figure 4. Orbital contour diagrams for thioacetaldehyde $\mathrm{C}_{\mathrm{me}}-\mathrm{H}_{\mathrm{op}}$ bonding and $\mathrm{C}-\mathrm{S}(\sigma)^{*}$ antibonding pre-NBO (not orthogonal) in (a) eclipsed and (b) staggered conformations.

Table 4. Principal barrier-forming bond-antibond and lone-pair-antibond interaction terms from secondorder perturbation calculation for fully relaxed rotation of methyl group in thioacetaldehyde $\left(\mathrm{cm}^{-1}\right)^{\mathrm{a}}$.

\begin{tabular}{lc}
\hline Donor/acceptor & Barrier contribution $^{\mathrm{b}}$ \\
\hline $\mathrm{S}-\mathrm{C}(\sigma) / \mathrm{C}-\mathrm{H}_{\mathrm{op}}{ }^{* \mathrm{~b}, \mathrm{c}}$ & 129 \\
$\mathrm{~S}-\mathrm{C}(\pi) / \mathrm{C}-\mathrm{H}_{\mathrm{op}}{ }^{\mathrm{b}, \mathrm{c}}$ & 283 \\
$\mathrm{C}-\mathrm{H}_{\mathrm{ald}} / \mathrm{C}-\mathrm{H}_{\mathrm{ip}}{ }^{*}$ & 647 \\
$\mathrm{C}_{-} \mathrm{H}_{\mathrm{ip}} / \mathrm{C}-\mathrm{H}_{\mathrm{ald}}{ }^{*}$ & 1032 \\
$\mathrm{C}-\mathrm{H}_{\mathrm{op}} / \mathrm{S}-\mathrm{C}(\sigma)^{* \mathrm{~b}, \mathrm{c}}$ & 1077 \\
$\mathrm{C}-\mathrm{H}_{\mathrm{op}} / \mathrm{S}-\mathrm{C}(\pi)^{* \mathrm{~b}, \mathrm{c}}$ & 311 \\
$\mathrm{LP}(1) / \mathrm{C}-\mathrm{C}^{*}$ & 84 \\
$\mathrm{LP}(1) / \mathrm{C}-\mathrm{H}_{\mathrm{ip}}{ }^{*}$ & 94 \\
$\mathrm{LP}(2) / \mathrm{C}-\mathrm{H}_{\mathrm{ald}}$ & 133 \\
\hline
\end{tabular}

${ }^{\mathrm{a}}$ See footnote (a) table $2 ;{ }^{\mathrm{b}}$ where there are multiple identical interactions, the contribution of only one is given; ${ }^{c}$ there are two such interactions

staggered conformers. Again, these interactions show good overlap of the orbital (Fock matrix element, equal to 0.068 a.u.) in the eclipsed conformer and a relatively weak overlap (Fock matrix element equal to 0.036 a.u.) in the staggered conformer. Thus, here too there is charge transfer from the $\mathrm{C}-\mathrm{H}_{\mathrm{ip}}$ bond to the $\mathrm{C}-\mathrm{H}_{\text {ald }}$ antibonding orbital.

The interaction energy between $\mathrm{C}-\mathrm{H}_{\text {ald }}$ bonding and $\mathrm{C}-\mathrm{H}_{\mathrm{ip}}$ antibonding is $647 \mathrm{~cm}^{-1}$ and it appears as the barrier-forming one. The contour diagram shown in figures $6 \mathrm{a}$ and $\mathrm{b}$, illustrate similar decreased overlap in going from the eclipsed to the staggered conformer. 
a

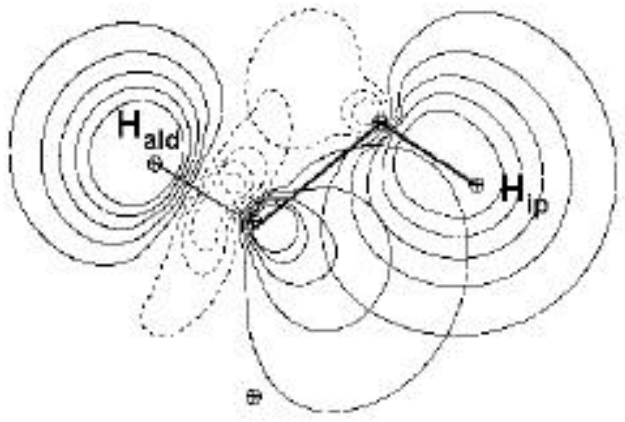

b

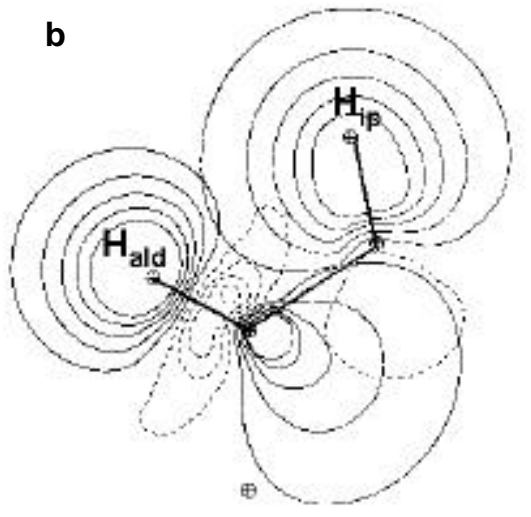

Figure 5. Orbital contour diagrams showing overlap of thioacetaldehyde $\mathrm{C}_{\mathrm{me}}-\mathrm{H}_{\mathrm{ip}}$ bonding and $\mathrm{C}-\mathrm{H}_{\text {ald }} *$ antibonding pre-NBOs.

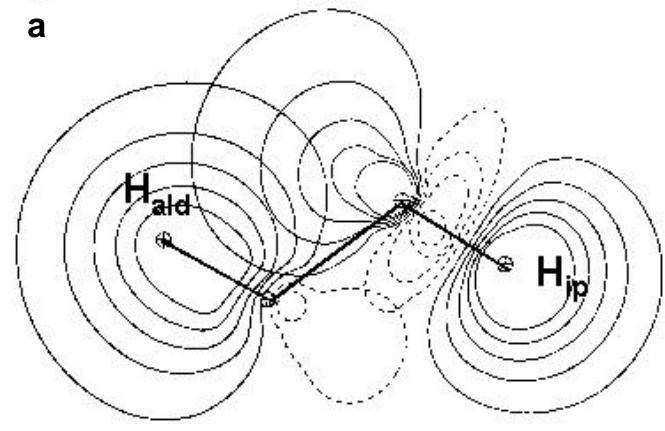

$\rightarrow$

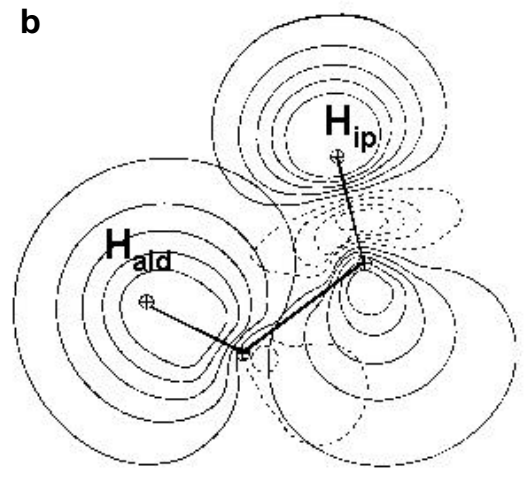

(1)

Figure 6. Orbital contour diagrams showing overlap of thioacetaldehyde $\mathrm{C}-\mathrm{H}_{\mathrm{add}}$ bonding and $\mathrm{C}_{\mathrm{me}}-\mathrm{H}_{\mathrm{ip}}$ * antibonding pre-NBOs.

Three other terms which appear as barrier-forming bond-antibond interactions are $\mathrm{S}-\mathrm{C}(\sigma) / \mathrm{C}-\mathrm{H}_{\mathrm{op}} *, \mathrm{C}-\mathrm{S}(\pi) / \mathrm{C}-\mathrm{H}_{\mathrm{op}} *$ and $\mathrm{C}-\mathrm{H}_{\mathrm{op}} / \mathrm{C}-\mathrm{S}(\pi)^{*}$. Charge transfer interaction from the $\mathrm{C}-\mathrm{S}(\pi)$ bonding orbital to the $\mathrm{C}-\mathrm{H}_{\mathrm{op}} *$ antibond is important. However, the barrierforming interaction seems to be less important than the $\sigma$ interaction, and the sum of the barrier-forming $\pi$ bond-antibond interactions is far less than the sum of the $\sigma$ interactions.

Lone-pair antibond interactions which contribute to the barrier are very small. Barrierforming lone-pair antibond interactions are $\mathrm{LP}(1) / \mathrm{C}-\mathrm{C}^{*}, \mathrm{LP}(1) / \mathrm{C}-\mathrm{H}_{\mathrm{ip}}{ }^{*}$ and $\mathrm{LP}(2) /$ $\mathrm{C}-\mathrm{H}_{\mathrm{ald}} *$ (table 4). The contour diagrams for these interactions are shown in figures 7-9. 

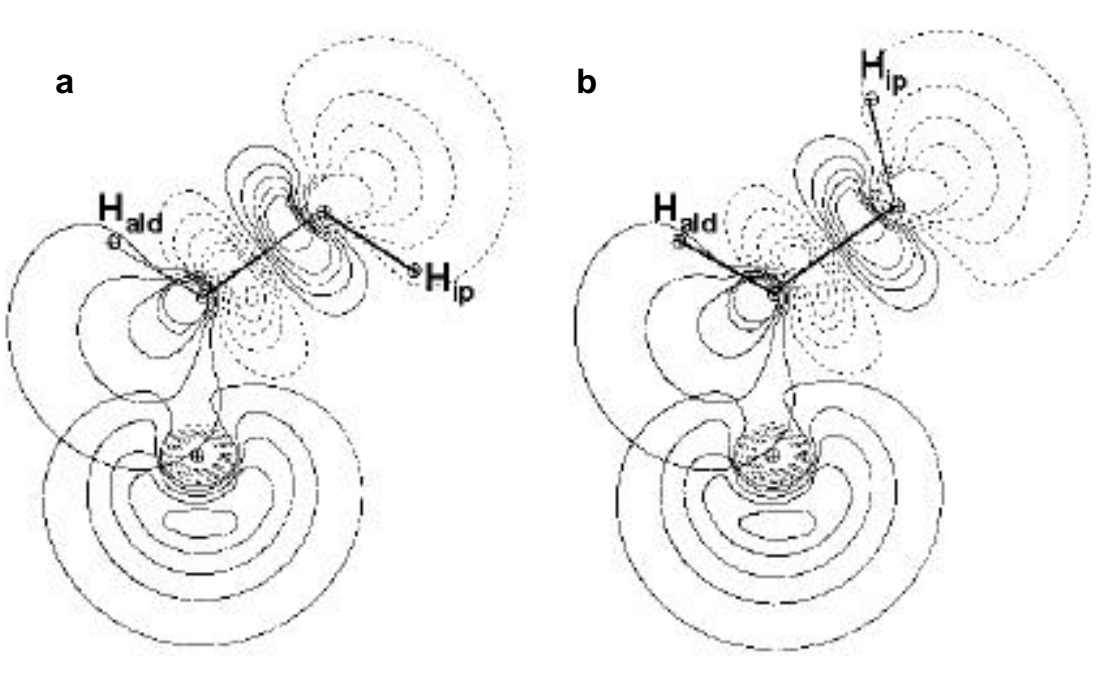

Figure 7. Orbital contour diagrams showing overlap of thioacetaldehyde LP(1) bonding and $\mathrm{C}-\mathrm{C}^{*}$ antibonding pre-NBOs.
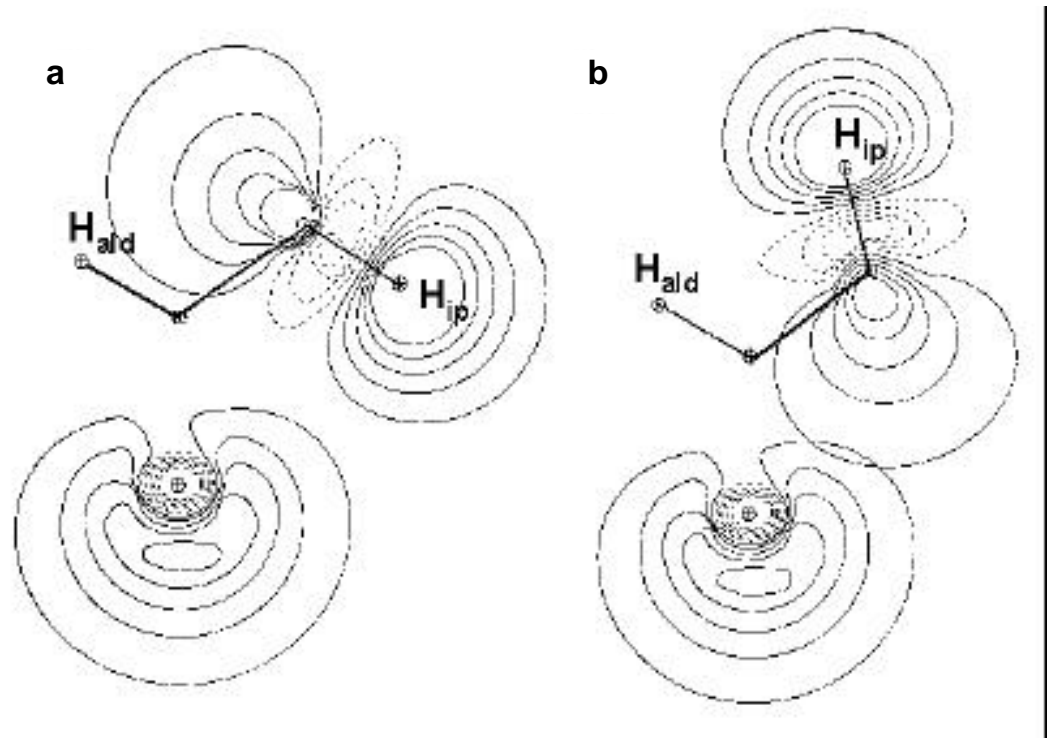

Figure 8. Orbital contour diagrams showing overlap of thioacetaldehyde LP (1) bonding and $\mathrm{C}_{\mathrm{me}}-\mathrm{H}_{\mathrm{ip}}$ * antibonding pre-NBOs.

\subsection{Weakening of bonds}

Weakening of the $\mathrm{C}-\mathrm{C}$ bond $(0.008 \AA$ ) can only be explaied by considering the overlap of the unorthogonalized NBO involved in the barrier-forming bond-antibond interaction terms shown in figures 4-6. For all cases the large bonding overlap in the eclipsed conformer becomes the antibarrier in the $\mathrm{C}-\mathrm{C}$ bond region of the staggered conformer 

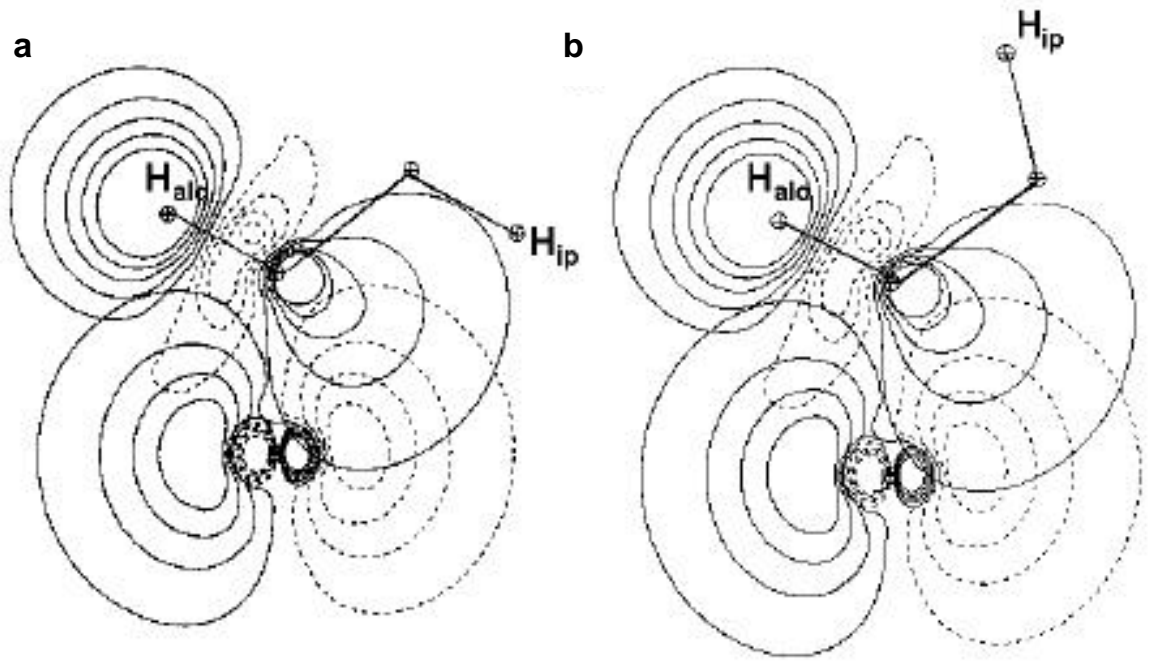

Figure 9. Orbital contour diagrams showing overlap of thioacetaldehyde LP(2) bonding and $\mathrm{C}-\mathrm{H}_{\text {ald }} *$ antibonding pre-NBOs.

resulting in weakening of the $\mathrm{C}-\mathrm{C}$ bond. Weakening of the $\mathrm{C}-\mathrm{C}$ bond in acetaldehyde also arises from a large overlap of the interacting orbitals in the equilibrium conformer compared to those of the staggered one ${ }^{16}$. The contour diagrams (figures $4-6$ ) show that the bonding overlap in the equilibrium conformation is strongly reduced on going to the top-of-the-barrier. Thus, the decrease in overlap involving the back and forth charge transfer between the interacting orbitals results in the $\mathrm{C}-\mathrm{C}$ bond lengthening.

The cause of $\mathrm{C}-\mathrm{S}$ bond weakening is, however, not so clear. The electron transfer from the $\mathrm{C}_{\mathrm{me}}-\mathrm{H}_{\mathrm{op}}$ bonding orbital to the $\mathrm{C}-\mathrm{S}(\sigma)^{*}$ antibonding orbital and from the $\mathrm{C}-\mathrm{S}(\sigma)$ bonding orbital to the $\mathrm{C}_{\mathrm{me}}-\mathrm{H}_{\mathrm{op}}$ * antibonding orbital may be the cause of $\mathrm{C}-\mathrm{S}$ bond lengthening. Addition of electron to antibonding orbital or removal of electron from the bonding orbital could also weaken the bond to some degree.

\subsection{Steric repulsion}

The Pauling exchange interaction has been calculated using Bakenhoop and Wienhold formulation. The contributions of Pauling exchange repulsions to internal rotational barrier are shown in table 5. The main barrier forming Pauling exchange terms are between $\mathrm{S}-\mathrm{C}(\sigma)$ bond $/ \mathrm{C}_{\mathrm{me}}-\mathrm{H}_{\mathrm{ip}}$ bond and $\mathrm{C}-\mathrm{H}_{\mathrm{ald}}$ bond/ $\mathrm{C}_{\mathrm{me}}-\mathrm{H}_{\mathrm{op}}$ bond (table 5).

\section{Conclusions}

Owing to the use of a relatively less powerful model by Moule et $a l^{20}$ the agreement between the theoretical evaluated rotational barrier of methyl group in thioacetaldehyde and the experimental found value was rather poor. Our reinvestigation of the problem in terms of NBO analysis, relaxation effect and Pauling exchange interaction calculations provided a significantly better concordance enabling us to conclude the following. (1) 
Table 5. Principal Pauling exchange repulsion changes accompanying fully relaxed methyl internal rotations in thioacetaldehyde $\left(\mathrm{cm}^{-1}\right)^{\mathrm{a}}$.

\begin{tabular}{lc}
\hline Interaction & Barrier contribution \\
\hline $\mathrm{S}-\mathrm{C}(\sigma) / \mathrm{C}_{\mathrm{me}}-\mathrm{H}_{\mathrm{ip}}$ & 899 \\
$\mathrm{~S}-\mathrm{C}(\pi) / \mathrm{C}_{\mathrm{me}}-\mathrm{H}_{\mathrm{op}}$ & 98 \\
$\mathrm{C}-\mathrm{H}_{\mathrm{ald}} / \mathrm{C}_{\mathrm{me}}-\mathrm{H}_{\mathrm{op}}$ & 458 \\
$\mathrm{C}-\mathrm{H}_{\mathrm{ald}} / \mathrm{LP}(2)$ & 105 \\
\hline
\end{tabular}

${ }^{\mathrm{a}}$ Values are nearest whole numbers; ${ }^{\mathrm{b}}$ there are two such repulsions

The methyl rotational barrier for the fully relaxed rotation originates from the nuclearelectron attraction term as it happens in the case of acetaldehyde. This nuclear-electron attraction term appears as an anti barrier in the case of rigid rotation. The $\mathrm{C}-\mathrm{C}$ relaxation alone provides the nuclear-electron attraction term as methyl rotational barrier. (2) The results of natural bond orbital analysis shows that the principal barrier forming term originates from the $\mathrm{C}-\mathrm{C}$ bond. Whereas for acetaldehyde the $\mathrm{C}-\mathrm{C}$ and $\mathrm{C}-\mathrm{Hop}$ bond energies appear to be the barrier forming terms, for thioacetaldehyde $\mathrm{C}-\mathrm{Hop}$ bond appears as an antibarrier. The $\mathrm{C}-\mathrm{S}$ bond contribution to the barrier is one-third that of the $\mathrm{C}-\mathrm{C}$ bond and the bond length increases in the top-of-the-barrier. (3) The lengthening of $\mathrm{C}-\mathrm{C}$ bond in the staggered conformer can, however, be explained by considering several (figures 4-7) bond-antibond interaction terms which provide a more favourable bonding overlap in the $\mathrm{C}-\mathrm{C}$ bond region for the eclipsed conformer compared to that of the staggered one. The back and forth charge transfer within these bond-antibond orbitals make the $\mathrm{C}-\mathrm{C}$ region for the eclipsed conformer to be more bonding in character while a similar region for the staggered conformer is antibonding in nature.

\section{Acknowledgements}

The author acknowledges his indebtedness to Prof Lionel Goodman of Rutgers University, USA, who has initiated him in this type of calculation. He also thanks Prof Naohiko Mikami and Prof T Ebata of Tohoku University, Japan for allowing him to carry out this work at their computer facility. Thanks are due to Prof Mihir Chowdhury of the Indian Association for the Cultivation of Science, Calcutta, for helpful discussions.

\section{References}

1. Groner P, Sullivan J F and Durig J R 1981 Vibrational spectra and structure (Amsterdam: Elsevier) vol 9, pp 405-496

2. Goodman L and Pophristic V 1998 The encyclopedia of computational chemistry (John Wiley \& Sons: Chichester) vol. 4, pp 2525-2541; Goodman L, Pophristic V and Weinhold F Acc. Chem. Res. (accepted)

3. Lister D G, MacDonald J N and Owen N L 1978 Internal rotation and inversion: An introduction to large amplitude motions in molecules (New York: Academic Press)

4. Veillard A 1974 In Internal rotation in molecules (New York: John Wiley and Sons) pp 385421

5. Goodman L and Gu H 1998 J. Chem. Phys. 10972

6. Goodman L, Gu H and Pophristic V 1999 J. Chem. Phys. 1104268 
7. Goodman L and Pophristic V 1996 Chem. Phys. Lett. 259287

8. Pophristic V, Goodman L and Guchhait N 1996 J. Phys. Chem. 10192

9. Thakur S N, Guo D, Kundu T and Goodman L 1992 Chem. Phys. Lett. 199 335; Philis J G and Goodman L 1993 J. Chem. Phys. 983795

10. Kleiner I, Hougen J T, Suenram R D, Lovas F J and Godefroid M 1991 J. Mol. Spectrosc. 148 38

11. Belov S P, Tretyakov M Yu, Kleiner I and Hougen T J 1993 J. Mol. Spectrosc. 16061

12. Leszcynski J and Goodman L 1993 J. Chem. Phys. 99 4867; Goodman L, Leszczynski J and Kundu T 1994 J. Chem. Phys. 1001274

13. Hehre W J, Pople J A and Devaquet A J P 1976 J. Am. Chem. Phys. 98664

14. Sovers O J, Kern C W, Pitzer R M and Karplus M 1968 J. Chem. Phys. 49 2592; Pitzer R M 1983 Acc. Chem. Res. 16 207; Jorgensen W L and Allen L C 1971 J. Am. Chem. Soc. 93 567; Munoz-caro C, Nino A and Moule D C 1994 Theor. Chim. Acta. 88 299; Hadad C M, Foresman J B and Wiberg K B 1993 J. Phys. Chem. 944293

15. Goodman L, Kundu T and Leszczynski J 1995 J. Am. Chem. Soc. 1172082

16. Guo D and Goodman L 1996 J. Phys. Chem. 10012540

17. Kroto H W and Landsberg B M 1976 J. Mol. Spectrosc. 62346

18. Judge R H, Moule D C, Bruno A E and Steer R P 1983 Chem. Phys. Lett. 102385

19. Paone S, Moule D C, Bruno A E and Steer R P 1984 J. Mol. Spectrosc. 1071

20. Moule D C, Smeyers Y G, Senenet M L, Clouthier D J, Karolczak J and Judge R H $1991 \mathrm{~J}$. Chem. Phys. 953137

21. Judge R H, Moule D C, Bruno A E and Steer R P 1987 J. Chem. Phys. 87 60; Smeyers Y G, Nino A and Bellido M N 1988 Theor. Chim. Acta 74259

22. Smeyers Y G, Nino A and Moule D C 1990 J. Chem. Phys. 935786

23. Ab-initio calculation program, Gaussian 94, Frisch M J et al Gaussian Inc., Pittsburgh PA, 1995

24. Reed A E and Weihold F 1983 J. Chem. Phys. 784066

25. NBO 4.0. Glendening E D, Badenhoop J K, Reed A E, Carpenter J E and Weinhold F 1996 Theoretical Chemistry Institute, University of Wisconsin, Madison

26. Foster J P and Weinhold F 1980 J. Am. Chem. Soc. 1027211

27. Badenhoop J K and Weihold F 1997 J. Chem. Phys. 107 5406; Badenhoop J K and Weihold F 1997 J. Chem. Phys. 1075422

28. Guchhait N (unpublished results)

29. Reed A E and Weinhold F 1983 J. Chem. Phys. 784066

30. Reed A E, Curtiss L A and Weinhold F 1988 Chem. Rev. 88899

31. Reed A E and Weinhold F 1991 Isr. J. Chem. 31277 